THE KURUME MEDICAL JOURNAL Vol. 4, No. 1, 1957

\title{
BIOCHEMICAL RESEARCH ON THE INFLUENCE OF PLACENTA PLASMA UPON THE LIVER INJURY CAUSED BY CARBON TETRACHLORIDE
}

\author{
EIJI KIMOTO, MAKIO KAKIZOE, YASUE IMOTO AND \\ MASAZUMI MASUMOTO \\ Department of Pathology, Kurume University School of Medicine and \\ Research Institute of Tissue Regeneration, Kurume-shi, Japan
}

One of the present authors (1) reported that Placenta Plasma and Neo Placenta Plasma $(2,3)$ prevent or remove an accumulation of excess fat in the liver of rat followed by administration of carbon tetrachloride.

In this work, further detailed studies on the lipotropic action of Placenta Plasma were performed by the biochemical methods.

Ten years ago, the mechanism of lipotropic action was indicated by Perlman, Chaikoff, Welch, Landau and Du Vigneaud $(4,5)$. They settled a hypothesis that the lipotropic agent is incorporated into the phospholipid molecule which facilitates in some manner to transport and to metabolize fatty acids, and that dietary choline is rapidly incorporated into liver lecithin and methionine exerts its lipotropic effect by denoting its labile methyl group for biosynthesis of choline.

Perlman (6), Artom (7) and Cornatzer (8) found that choline or methionine accelerates the rate of turnover of the phosphorous in the phosphatides while cholin deprivation retards the rate of incorporation of new choline into the phosphatides which is synthesized mainly in the liver.

Lichtman (4) said that both lecithin formation and fatty acid metabolism probably depend upon the concentration of free choline in the liver cells, but there is no conclusive evidence for the hypothesis that the prevention of the fatty infiltration is the result of an increased turnover of liver phospholipids.

According to the recent investigations it seems more likely that the lipotropic effect of choline and methionine may result, at least to a large extent, from the enhancement of fatty acid oxidation in the liver itself rather than by promoting the fat mobilization in the form of plasma phospholipids.

Artom (9) found that the oxidation of isotopic long chain fatty acids is depressed in the liver preparations of choline-deficient animals, and that choline, administered in vivo, restores the ability of tissue to oxidize the labile fatty acids at a high rate.

Recently, the significance of coenzyme $A$ on the fat metabolism is recognized. 
And it is considered as an area to be studied very actively in the next few years that the formation of acetyl coenzyme A may be sensitive to the deprivation of sulfur amino acids or panthothenic acid in animal (10).

The present authors studied on the relation between the fatty accumulation and the metabolic disturbance of liver administered by carbon tetrachloride and intended to clarify the mode of action of Placenta Plasma on the liver injury.

\section{MATERIALS AND METHODS}

The male rats of Wistal strain ranging from 3 to 4 months of age were employed. A single dose of $0.5 \mathrm{ml}$ of 50 per cent $\mathrm{CCl}_{4}$ in olive oil was injected subcutaneously. And experimental animals were divided into three groups.

In the 1st group (control group) - -, $\mathrm{CCl}_{4}$ alone is in jected.

In the 2nd group- $-\mathrm{O}_{-}$, single dose of $\mathrm{CCl}_{4}$ and two doses of $0.2 \mathrm{ml}$ of P. P.* (Neo Placenta Plasma) are administered respectively one day and one hour before $\mathrm{CCl}_{4}$ in jection.

In the 3rd group-- $-\triangle-\cdots$, two doses of P. P. before $\mathrm{CCl}_{4}$ injection and daily one does of $\mathrm{P}$. P. after $\mathrm{CCl}_{4}$ injection until death are administered.

And normal one is without both $\mathrm{CCl}_{4}$ and P. P. administration.

Animals were killed after the definite time from $\mathrm{CCl}_{4}$ injection. The removed tissue of rat liver was used for the following measurements.

Fatty content: The long chain fatty acids and their esters are determined by the Smith and Kik's method (11). An excised tissue is saponified with saturated potassium hydroxide and the fatty acids are precipitated with dilute sulfuric acid. The fatty acids are extracted in petrolium ether, washed with boiled distilled water in order to free from traces of inorganic acid and titrated with approximately $0.02 \mathrm{M}$ potassium alcoholate. As potassium alcoholate is unstable, it is, before use, standarized against a definite concentration of palmitic acid in petcolium ether. Unit in figures shows an amount of palmitic acid being equivalent to the measured fatty acid per $1 \mathrm{gm}$ of experimental material.

One of the present authors (1) recognized that the fatty content determined chemically is nearly parallel with the extent of fatty accumulation estimated morphologically with sudan III staining.

Water content: Liver slice of definite weight is dried up at $105^{\circ} \mathrm{C}$ for 24 hours. And the weight of dried material is measured. Water content is estimated as

*P. P. (Neo Placenta Plasma) is made by digestion of cold stored human placenta with pepsine. 
$\frac{\text { wet weight-dry weight }}{\text { wet weight }} \times 100 \%$.

Assay of coenzyme A: Aromatic amine such as sulfanilamide and p-aminoazobenzene is acetylated by coenzyme A with a copresence of apoenzyme and ATP. This reaction is utilized for an assay of coenzyme A by Kaplan et al. (12) and Handschumacher et al. (13) The author used the Kaplan's assay method as follows.

To each tube there added

1) $0.3 \mathrm{ml}$ of the solution to be tested for coenzyme activity (about $1 \mathrm{~g}$ of the excised liver of experimental animal is added to $3 \mathrm{ml}$ of water, boiled for 5 minutes and centrifuged. The supernatant is used for an assay).

2) $0.3 \mathrm{ml}$ of the assay reaction mixture (mixture of $10 \mathrm{ml}$ of $0.004 \mathrm{M}$ sulfanilamine, $2.5 \mathrm{ml}$ of $\mathrm{M}$ sodium acetate, $8 \mathrm{ml}$ of $0.05 \mathrm{M}$ sodium adenosine triphosphate and $10 \mathrm{ml}$ of $0.5 \mathrm{M}$ sodium citrate $\mathrm{pH}$. 7.0)

3) $0.08 \mathrm{ml}$ of a freshly prepared $\mathrm{M}$ sodium bicarbonate solution.

4) $0.1 \mathrm{ml}$ of a freshly prepared $0.1 \mathrm{M}$ cysteine hydrochloride.

5) $0.25 \mathrm{ml}$ of the aged apoenzyme (aged at $25^{\circ} \mathrm{C}$ for 4 hours) of pigeon liver. Each tube contains $0.1 \mathrm{ml}$ of $0.004 \mathrm{M}$ sulfanilamide.

A blank is prepared by adding all the constituents except coenzyme. The tubes are stoppered, mixed, and incubated for 2 hours in a water bath of $37^{\circ} \mathrm{C}$. The reaction is halted by adding $4 \mathrm{ml}$ of 5 per cent trichloroacetic acid. After centrifugation, aliquots of $2 \mathrm{ml}$ are taken for sulfanilamide determination, carried out by the procedure of Bratton and Marshal (14). Readings are made by photoelectric colorimeter, filter 54. From the difference in sulfanilamide between the blank and the tubes containing coenzyme, the amount of sulfanilamide acetylated is determined. Unit of coenzyme $\mathrm{A}$ in figures shows $\mathrm{ml}$ of $0.004 \mathrm{M}$ acetylated sulfanilamide per $1 \mathrm{~g}$ of liver tissue.

$\mathrm{Qo}_{2}$ of liver slice (cubic millimeters of oxygen uptake per milligrams dry tissue per hour): Liver slice about $0.5 \mathrm{~mm}$ thick, weighing about $200 \mathrm{mg}$ are prepared and incubated in Warburg vessels at $37^{\circ} \mathrm{C}$ in an atmosphere. $1 \mathrm{ml}$ of Ringer solution was used as an incubation medium.

Activity of succino-dehydrogenase of liver homogenate: The excised tissue of liver is added to phosphate buffer solution being 20 times as liver weight $(\mathrm{pH} 7.0$ ) and homogenized. $1 \mathrm{ml}$ of liver homogenate and $0.2 \mathrm{ml}$ of sodium succinate (adjusted to $\mathrm{pH}$ 7.0) are put, respectively, into a main room and a side room of Warburg vessel. The amount $(\mu \mathrm{l})$ of oxygen uptake per hour at $37^{\circ} \mathrm{C}$ is measured.

This work was performed from January to March. 


\section{RESULTS AMD DISCUSSION}

At first day after $\mathrm{CCl}_{4}$ injection, fatty content of liver in the 2nd and 3rd group is lower than that of the control group in agreement with Kakizoe's results. But on the contrary, at the next few days, fatty content of the 2nd group is rather inclined to be higher than that of the control group. Two doses of P. P. before $\mathrm{CCl}_{4}$ injection are likely to cause a momentary fatty accumulation.

In our institute, it was recognized that $P$. P. contains a considerable amount of lipotropic agents such as methionine and choline but a lower amount of anti-lipotropic substances such as cystine. Magara et al. (15) found that some of placentalextracts administered intravenously into the pregnant animal caused a liver necrosis. So that, there may be a possibility that P. P. damages the liver cells in a certain condition.

Fatty content of the 3rd group is usually lower than control case, i. e. the daily administration of P.P. prevents the fatty accumulation. After $6 \sim 8$ days from $\mathrm{CCl}_{4}$ injection, fatty content of the 2nd and 3rd group is slightly lower than that of the control group.

Water content is nearly in a reverse relation with fatty content. When fatty content is very high, water content is extremely low. This may be, at least, due to the hydrophobic nature of fat. At the early time after $\mathrm{CCl}_{4}$ injection, water content in all groups is higher than that of normal rat.

It is recognized by Stowell et al. $(16,17)$ that in $\mathrm{CCl}_{4}$ poisoing an early swelling of the extracentral cells of liver does occur and it is attributed to impared intralobular blood flow accordingly to centrolobular necrosis. This early swelling may be related to such a high water content. At this time, compared with the 1st and 2nd or 3rd group, water content of the latter is higher than that of the former. Though, in that time, fatty accumulation of the latter is lower than the former, at the next few days the latter (2nd group) is higher than the former. This higher fat accumulation might be due to such a stronger swelling.

At a few days after $\mathrm{CCl}_{4}$ injection, content of coenzyme A decreased fairly and later it returned to the normal level. But, compared with the 1 st and 2 nd or 3 rd group, the parallel relation between content of coenzyme $A$ and prevention of fat accumulation can not always be realized.

About at the occurrence of the fatty liver, intrinsic respiration of liver slice becomes lower than the normal level, but on the other hand the activity of succino-dehydrogenase becomes higher. These two activities later return to normal as repair is effected. There are rather a considerable close relation between the increase in fatty accumulation 
and the promotion of succino-dehydrogenase activity.

It was observed by Slater and his colleagues (18) that the percentage increase in oxygen consumption of the tissue slices or suspensions after the addition of excess metabolite (succinate or p-phenylenediamine) over that of the same samples of tissues alone is invariably smaller in the case of neoplastic than normal tissues and that malignant tissues, in comparison with normal tissues, are characterized not only by possessing the low concentration of cytochrome $\mathrm{C}$ but also by possessing the disparity between the components of the cytochrome oxidase-cytochrome $\mathrm{C}$ system.

In $\mathrm{CCl}_{4}$ poisoning the relation between these two activities is just reverse with that of neoplastic tissue, i. e. the activity of succino-dehydrogenase activity is abnormally promoted inspite of a lower intrinsic respiration.

Gurin (10) said at the conference on Liver Injury that, in the case of the liver slices obtained from an alloxan diabetic animals, apparently oxidation was proceded at an accelerated rate, and yet, if we put in labeled acetate or pyruvate, there was very little incorporation into fatty acids.

In order to elucidate the pathogenesis of fatty liver due to $\mathrm{CCl}_{4}$ administration from the viewpoint of metabolic disturbance of liver cells, more detailed studies on such themes must be performed.

\section{SUMMARY}

Biochemical research on the pathogenesis of fatty liver due to $\mathrm{CCl}_{4}$ administration was performed. At a few days after $\mathrm{CCl}_{4}$ injection, a high amount of fat was accumulated in a liver, being preceded with swelling of liver cells. About at that time, a concentration of coenzyme $A$ and an oxygen consumption of liver slice became lower than normal level. But the activity of succino-dehydrogenase became rather higher than normal.

By the administration of Neo Placenta Plasma, an early fatty infiltration was prevented and yet after a few days a momentary fatty accumulation was caused to a considerably high extent. But later its recovery was more actively effected. That is, it was found that Neo Placenta Plasma showed a dual effect on the fatty accumulation at a certain condition.

\section{ACKNOWLEDGMENT}

The authors wish to express with gratitude to Professor K. Hiyeda, M. Takeuchi and Assistant Professor T. Nakashima for the direction and advice they have given during the progress of this study. 
CASE 1.

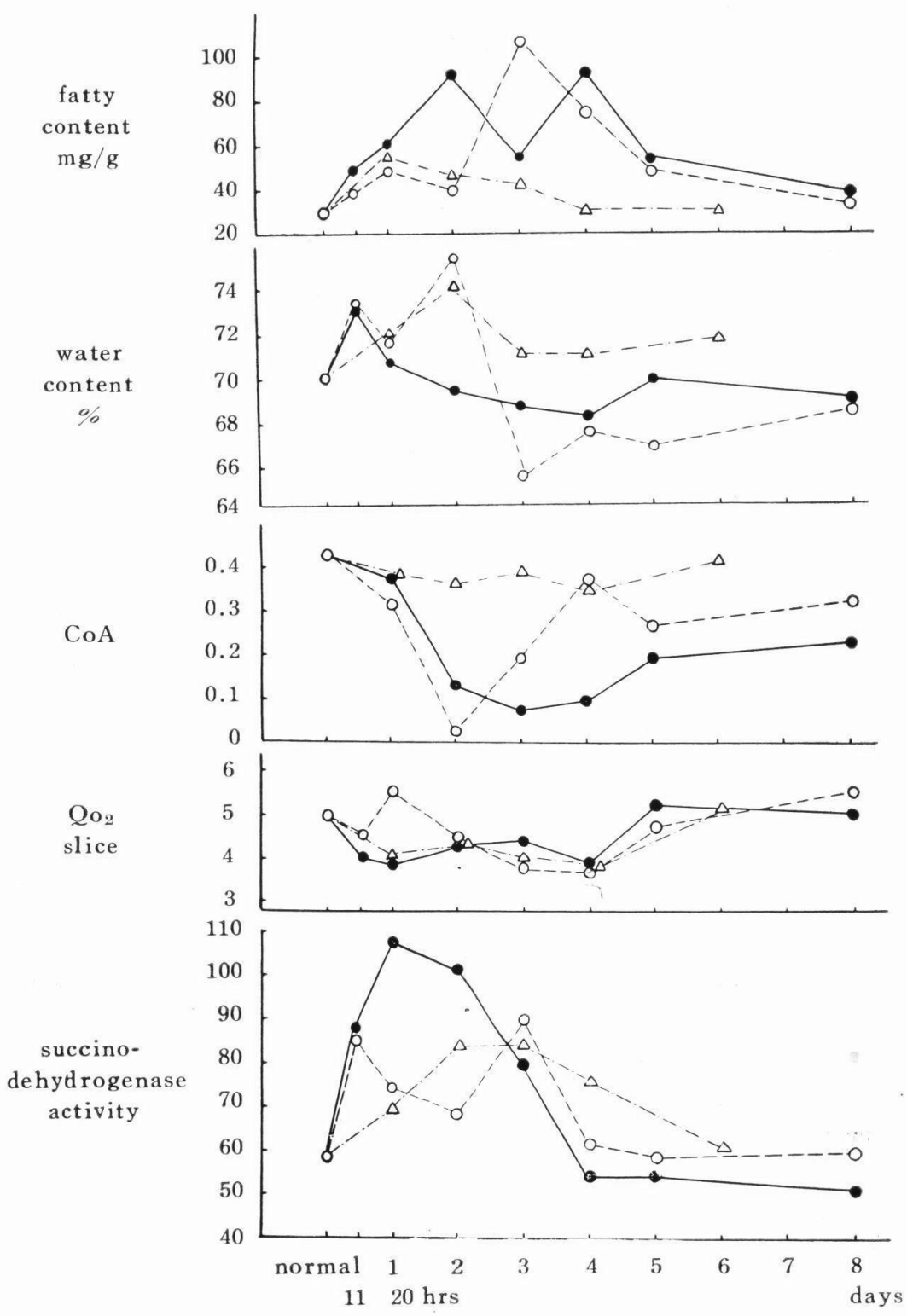


CASE 2.

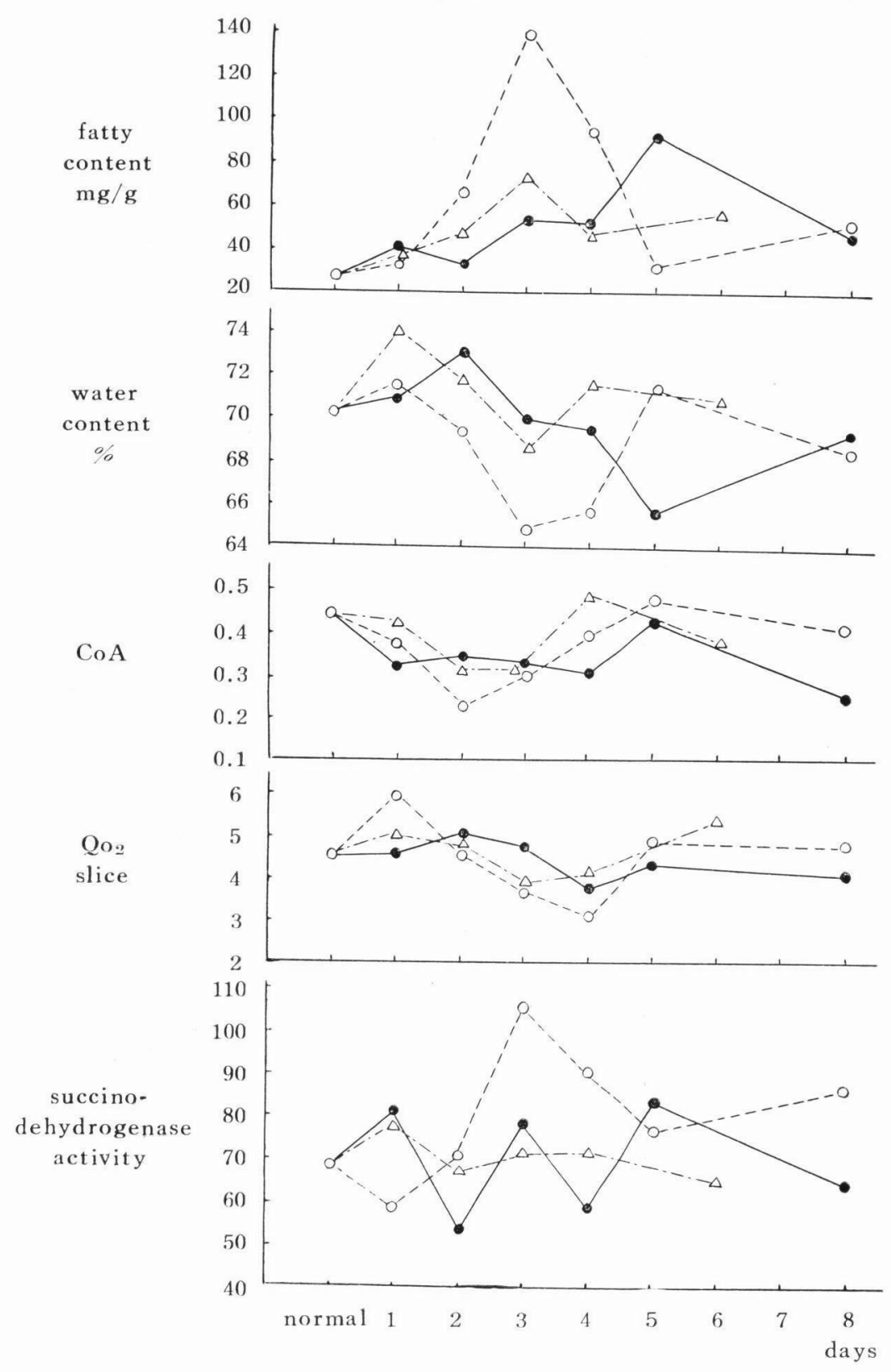




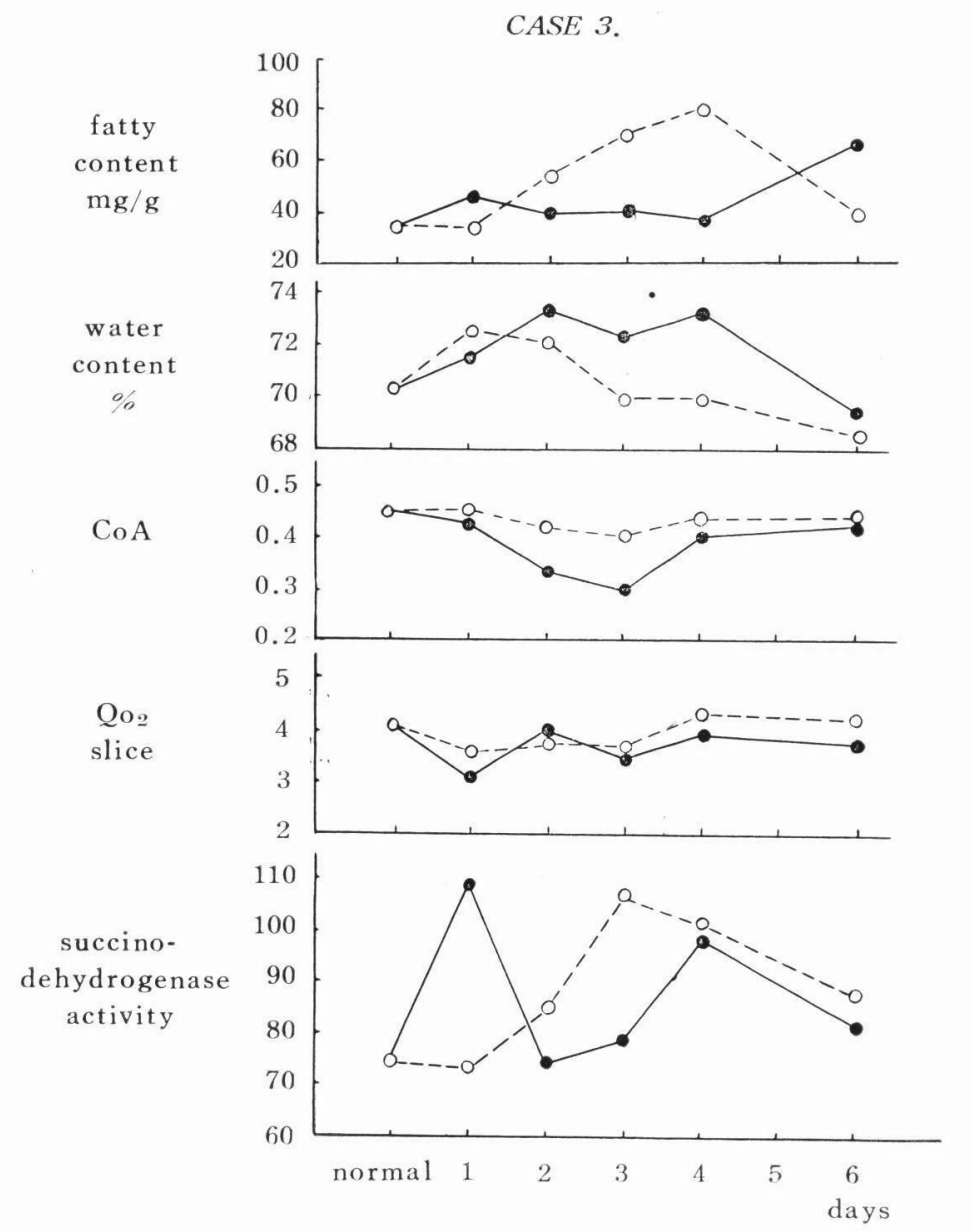

\section{REFERENCES}

1. Kakizoe, M.: Studies on the lipotropic action of Placenta Plasma. J. Kurume Med. Assoc., in press.

2. Hiyeda, K.: Method of Treatment by Placenta Plasma and Nervism Pathology. Japanese Cultural Association, Tokyo (1955).

3. Kimoto, E. And KaKizoE, M.: Effect of temperature on the autolysis of cold stored human Placenta. Kurume Med. J., Vol. 2, p. 153, 1955.

4. Lichtman, S. S.: Diseases of the Liver, Gallbladder and Bile Ducts., Vol. 1 Lea and Febiger, 1953.

5. Takahashi, T.: Some problems on the fatty liver. Saishin Igaku, Vol 10, p. 66, 1955.

6. Perlman, I, Stillman, N. and Chaikoff, I. L : Radioactive phosphorous as an indica- 
tor of phospholipid metabolism. XI. The inftuence of methionine, cystine and cysteine upon phospholipid turnover in the liver. J. Biol. Chem., Vol. 133, p. 651, 1940.

7. Artom, C. and Connatzer, W. E.: The action of choline and fat on the lipid phosphorylation in the liver. J. Biol. Chem., Vol. 171, p. 779, 1947.

8. Cornatzer, W. E. et al.: Radioactive phosphorous as an indicator of the rate of phospholipid formation in patients with liver disease. Gastroenterology., Vol. 14, p. $1,1950$.

9. Artom, C.: Role of choline in the oxidation of fatty acids by the liver. J. Biol. Chem., Vol. 205, p. 101, 1953.

10. Gurin, S.: The liver and fat metabolism. Liver Injury. Trans. of the twelfth Conference. p. $67,1954$.

11. SMITh, M. E. AND KIK, M. C.: A micromethod for the determination of fatty acids from small amounts of whole blood. J. Biol. Chem., Vol. 103, p. 391, 1933.

12. Kaplan, N. O. and Lipmann, F.: The assay and distribution of coenzyme A. J. Biol. Chem., Vol. 174, p. 37, 1948.

13. Handschumacher, R. E. et al.: An improved enzymatic assay for Co-A. J. Biol. Chem., Vol. 189, p. 335, 1951,

14. Bratton, A. C. and Marshall, E. K.: A new coupling component for sulfanilaminde determination. J. Biol. Chem., Vol. 128, p. 537, 1939.

15. TANAKA, Y.: Studies on the histological findings in rabbit liver following the injection of the human placental extracts. J. Japanese Obst. \& Gynecol., Vol. 7, p. 1, 1955.

16. Stowell, R. E. et al.: Histochemical studies of mouse liver after single feeding of carbon tetrachloride. Arch. Pathol., Vol. 50, p. 519, 1950.

17. Hornfr Andrews, W. H.: The pathogenesis of the liver lesion due to the administration of carbon tetrachloride. Ann. Trop. Med. Parasit., Vol. 42. p. 95, 1948.

18. Grefnstrin, J. P.: Biochemistry of Cancer. Academic Press. Inc. 1954. 